\title{
EFEKTIVITAS TEKNIK MODELING SIMBOLIS DALAM MENINGKATKAN HARGA DIRI REMAJA KELUARGA BROKEN HOME
}

\author{
Roro Kurnia Nofita R
}

Institut Agama Islam Al-Khairat Pamekasan

kurnianofita@alkhairat.ac.id

\begin{abstract}
This research was intended to measure the effectiveness of simbolic modelling technique to increase teenagers' self-esteem who come in broken home family. The subject for this study are 54 teenagers who come in broken home family at SMKN 1 and SMKN 3 Pamekasan. This research used purposive sampling. This research used experimental design with Randomized Two-groups Design, Post Test Only. Self-esteem scale used as the measurement of the research. The data analysis used independent sample t-test. The result of t-computed is 2.17 while $t$-table is $0.034(p<0.05)$. This indicates that there is significant different mean of control group and experiment group. Mean score of experiment group (mean=165.70) is greater than mean score of control group (mean $=147$. 89) it concludes that simbolic modelling technique effective to increase teenagers' self-esteem in broken home family.
\end{abstract}

Keywords: Simbolic modeling technique, self-esteem, broken home

Abstrak: Penelitian ini dilakukan untuk mengukur keefektifan teknik modelling simbolis dalam meningkatkan harga diri remaja yang kelurganya broken home, subjek dalam penelitian ini sebanyak 54 siswa di SMKN 1 dan SMKN 3 Pamekasan, penelitian ini menggunaka sampel purposive, yang dimana penelitian ini adalah penelitian ekspreimen dengan design Randomized Two groups Design, Post Test Only. Dalam mengukur harga diri menggunakan alat ukur penelitian. Hasil analisis data menggunakan indpendent sample t-test. Hasil pengukuran 2.17 $\mathrm{t}$-table dengan $0.034(\mathrm{p}<0.05)$. indikator dalam penelitian ini bahwa ada perbedaan antara kelompok kontrol dan kelompok eksperimen. Yang hasilnya skor kelompok eksperimen $($ mean $=165.70)$ lebih tinggi dari pada kelompok kontrol (mean=147.89), sehingga hasilnya bahwa teknik modelling simbolik efektid untuk meningkatkan harga diri remaja korban perceraian).

Kata kunci: Teknik Modeling Simbolis, self-esteem, broken home

\section{PENDAHULUAN}

Remaja berasal dari kata adolescence yang berarti tumbuh atau tumbuh menjadi dewasa. Istilah adolescence mempunyai arti yang lebih luas lagi yang mencakup kematangan mental, emosional sosial dan fisik (Hurlock, 1990). Secara umum masa remaja adalah individu yang sedang mengalami peralihan dari masa anak-anak menuju remaja lebih memperhatikan penampilannya. Perubahan secara kognitif yaitu remaja mulai mengalami kematangan dalam berpikir, menalar, dan belajar dan perubahan secara sosial yaitu remaja mulai mengalami perubahan dalam berhubungan atau bersosialisasi dengan orang lain, sedangkan perubahan secara emosional yaitu remaja mulai mengalami gejolak emosi (Santrock, 2007). 
Selama remaja mengalami proses perubahan-perubahan tersebut, remaja mulai mengevaluasi dirinya yaitu seberapa besar remaja mampu untuk menghadapi setiap perubahan yang dialami. Artinya, apabila di setiap perubahan yang dialami dianggap tidak sesuai dengan diri remaja kemudian tidak mampu mengevaluasi dirinya, sehingga ini pun dapat berdampak pada harga diri remaja. Harga diri adalah variabel psikologis yang memegang peranan penting dalam perkembangan sikap dan perilaku remaja. Santrock (2007) mengatakan bahwa remaja masih dalam situasi peralihan dan krisis dalam menemukan identitas dirinya sehingga perasaan berharga dan bernilai sangatlah dibutuhkan oleh remaja.

Harga diri dikatakan Coopersmith (Harre dan Lamb, 1996) sebagai evaluasi individu mengenai hal-hal yang berkaitan dengan dirinya, yang mengekspresikan sikap setuju atau tidak setuju dan menunjukkan tingkat individu meyakini dirinya sendiri sebagai mampu, penting, berhasil, dan berharga. Rosenberg (Harre dan Lamb, 1996) merumuskan bahwa harga diri adalah sikap positif atau negatif terhadap diri. Santrock (2007) mengatakan bahwa harga diri adalah suatu dimensi evaluasi global mengenai diri dan disebut juga sebagai martabat diri (self-worth) atau gambaran diri (self image).

Harga diri termasuk kebutuhan dasar manusia yang dianggap penting oleh para peneliti dan klinisi dari berbagai disiplin ilmu (Guindon, 2010). Harga diri berkembang sesuai dengan kualitas interaksi individu dengan lingkungannya.

Harga diri remaja tidak luput dipengaruhi oleh peran lingkungan, salah satunya adalah lingkungan keluarga. Keluarga merupakan unit sosial terkecil yang memberikan fondasi primer bagi perkembangan anak (Kartono, 2003). Hubungan keluarga yang buruk merupakan bahaya psikologis pada setiap usia, terlebih selama masa remaja karena pada saat ini remaja sangat tidak percaya pada diri sendiri dan bergantung pada keluarga untuk memperoleh rasa aman. Remaja yang hubungan keluarganya kurang baik juga dapat mengembangkan hubungan yang buruk dengan orangorang di luar rumah (Hurlock, 1990).

Remaja yang akan dijadikan subjek dalam penelitian ini adalah remaja dari keluarga broken home yang disebabkan karena perceraian. Chaplin (2005) berpendapat broken home adalah menggambarkan keluarga yang tidak utuh, retak, tanpa kehadiran salah satu dari kedua orangtua yang disebabkan karena perceraian, meninggal atau meninggalkan keluarga.

Studi yang dilakukan oleh Baldwin dan Hoffman (Santrock, 2007) menemukan bahwa ketika kohesivitas keluarga meningkat, harga diri remaja juga akan meningkat seiring dengan bertambahnya usia. Kohesi keluarga tersebut didasarkan pada jumlah waktu yang digunakan oleh keluarga untuk berkumpul bersama, kualitas komunikasi, dan sejauh mana remaja dilibatkan dalam pengambilan keputusan keluarga. Remaja yang dibesarkan dari keluarga yang utuh maka perkembangan remaja akan mengarah kearah yang baik, namun sebaliknya jika remaja dibesarkan dari keluarga yang broken home dapat menyebabkan pengaruh-pengaruh negatif terhadap perkembangan sosial remaja.

Beberapa penelitian di Indonesia telah menunjukkan bahwa harga diri dapat ditingkatkan melalui asertivitas (Hidayati, 1995) selain itu berdasarkan penelitian yang dilakukan oleh Handayani, Muryantinah Mulyo, dkk. (1998) penerimaan diri dan harga diri dapat ditingkatkan melalui pelatihan pengenalan diri.

Remaja dari keluarga broken home lebih memiliki kecenderungan untuk mengalami masalah akademis, 
menunjukkan

masalah-masalah eksternal (seperti menyuarakan perasaan dan kenakalan) serta masalah internal (seperti kecemasan dan depresi), kurang memiliki tanggung jawab sosial, memiliki hubungan intim yang kurang baik, putus sekolah, aktif secara seksual di usia dini, menggunakan obat-obatan, berhubungan dengan peer yang antisosial, dan memiliki harga diri yang rendah (Santrock, 2007).

Remaja dapat meningkat harga dirinya setelah diberikan terror management (Baron, 2004). Remaja membutuhkan harga diri untuk merasa kompeten dan berguna dan pada saat yang sama membutuhkan pengakuan atas nilai dan kompetensi yang kita miliki dari orang lain. Kegagalan untuk diakui oleh diri sendiri atau oleh orang lain akan menimbulkan perasaan rendah diri dan kehilangan semangat atau putus asa (discouragement).

Mruk (2006) menyimpulkan ada empat kelompok dasar yang digunakan oleh para peneliti terdahulu sebagai teknik dalam meningkatkan harga diri, antara lain : Acceptance dan positive feedback merupakan bentuk dari penilaian oleh orang lain sebagai seorang yang berharga, yang menghubungkan seseorang dengan komponen harga diri. Modelling dan problem solving meningkatkan kompetensi dan merefleksikan sumber harga diri. Tiga teknik yang memerlukan kompetensi dan kebermanfaatan yaitu: cognitive restructuring menyangkut perubahan menjadi lebih kompeten dalam berpikir melalui cara yang berguna; assertiveness training berarti menjadi lebih terampil dalam membela hak pribadi sebagai makhluk hidup yang berharga; dan natural self esteem moments menantang harga diri pada kedua level tersebut. Kelompok tiga teknik terakhir, group, individual work, dan practice merupakan format unsur yang dapat berguna untuk membantu dalam menyesuaikan program untuk individu atau kelompok dengan karakteristik tertentu.

\begin{tabular}{|c|c|}
\hline \multicolumn{2}{|c|}{$\begin{array}{c}\text { Beberapa Teknik dalam Meningkatkan } \\
\text { Harga Diri (Murk, 2006) }\end{array}$} \\
\hline $\begin{array}{l}\text { Worthiness-Based } \\
\text { Techniques }\end{array}$ & $\begin{array}{l}\text { Competence-Based } \\
\text { Technique }\end{array}$ \\
\hline a. Acceptance & c. Modelling \\
\hline $\begin{array}{l}\text { b. } \\
\text { feedback }\end{array}$ & d. Problem solving \\
\hline $\begin{array}{l}\text { Competence- and } \\
\text { Worthiness-Based }\end{array}$ & $\begin{array}{l}\text { Common } \quad F \\
\text { Factors }\end{array}$ \\
\hline $\begin{array}{l}\text { e.Cognitive } \\
\text { restructuring }\end{array}$ & h. Group work \\
\hline $\begin{array}{l}\text { f.Assertiveness } \\
\text { training }\end{array}$ & i. Individual work \\
\hline $\begin{array}{l}\text { g.Natural self } \\
\text { esteem moments }\end{array}$ & j. Practice \\
\hline
\end{tabular}

Penelitian ini bertujuan untuk mengetahui efektivitas teknik modeling simbolis dalam meningkatkan harga diri remaja keluarga broken home.Penelitian ini menggunakan teknik modelling dalam meningkatkan harga diri remaja keluarga broken home yaitu dengan teknik modeling simbolis. Murk (2006) mengatakan bahwa modelling digunakan sebagai teknik dalam meningkatkan harga diri karena dapat meningkatkan kompetensi dan merefleksikan sumber harga diri. Modeling berakar dari teori Albert Bandura dengan teori belajar sosial. Bandura (Corey, 2005) mengatakan bahwa modelling adalah suatu strategi dalam konseling yang menggunakan proses belajar melalui pengamatan terhadap model dan perubahan perilaku yang terjadi karena peniruan.

Model dapat berupa model sesungguhnya (langsung) dan dapat pula simbolis. Model sesungguhnya adalah orang, yaitu konselor, guru atau teman sebaya. Konselor bisa menjadi model langsung dengan mendemonstrasikan tingkah laku yang dikehendaki dan mengatur kondisi optimal bagi konseli untuk menirunya. Modeling simbolis adalah salah satu teknik yang digunakan dalam psikoterapi dengan menggunakan film, video, buku cerita, 
novel, foto, rekaman audio, slide, dll untuk mencapai suatu tujuan. Teknik modeling simbolis merupakan salah satu metode yang sering digunakan dalam terapi kognitif-sosial, tujuannya adalah untuk memperbaiki regulasi self, melalui pengubahan tingkah laku dan mempertahankan perubahan tingkah laku yang terjadi (Alwisol, 2009).

Melalui modeling simbolis perilaku yang ingin diubah dan mengajarkan perilaku baru yaitu mengenai peningkatan harga diri remaja keluarga broken home ditampilkan oleh model, dengan tujuan perilaku yang diharapkan pada konseli dapat muncul dan tercipta perilaku baru. (Abimanyu dan Manrihu, 1996)

Penelitian ini dilakukan pada remaja keluarga broken home di SMK Negeri 1 dan SMK Negeri 3 Kabupaten Pamekasan. Hasil penelitian ini diharapkan dapat memberikan wawasan yang lebih luas bagi para remaja dalam meningkatkan harga dirinya dengan efektifitas teknik modeling simbolis.

Diagram dibawah ini adalah kerangka berfikir untuk menguji hipotesis yang menyatakan bahwa teknik modeling simbolis efektif dalam meningkatkan harga diri remaja keluarga broken home.

\section{METODE PENELITIAN}

Jenis penelitian yang digunakan adalah penelitian eksperimen. Seniati, dkk (2015) mengatakan bahwa penelitian eksperimen adalah observasi yang objektif terhadap suatu gejala yang dibuat agar terjadi dalam suatu kondisi yang terkontrol ketat, dimana satu atau lebih faktor dimanipulasi serta divariasikan dan faktor lain dibuat konstan, dengan tujuan untuk mempelajari hubungan sebab akibat

Desain eksperimen yang digunakan yakni: Randomized Two-groups Design, Posttest Only. Desain eksperimen ini adalah desain yang sudah memenuhi syarat dilakukannya penelitian eksperimental karena dilakukannya randomisasi. Desain ini menggunakan prinsip method of difference karena desain ini membuat dua kondisi yang berbeda pada dua kelompok penelitian (Seniati, dkk, 2015).

Kelompok eksperimen dalam penelitian ini diberi perlakuan (X) dan pada kelompok pembanding tidak diberi perlakuan. Sesudah selesai perlakuan kedua kelompok diberi tes (posttest) untuk mengukur kondisi akhir (0) yaitu untuk mengetahui adanya efektivitas dari perlakuan. Secara umum di skemakan seperti gambar berikut:

Desain penelitian Randomized TwoGroups Design, Posttest Only

\begin{tabular}{|cccc|}
\hline & $\mathrm{X}$ & $\rightarrow$ & $\mathrm{O}$ \\
$\mathrm{R}(\mathrm{KE})$ & $\cdots$ & & \\
$\mathrm{R}(\mathrm{KK})$ & & $\rightarrow$ & $\mathrm{O}$ \\
\hline
\end{tabular}

Keterangan :

$\mathrm{R}(\mathrm{KE})=$ Kelompok eksperimen

$\mathrm{R}(\mathrm{KK})=$ Kelompok kontrol

$\mathrm{X}=$ Perlakuan berupa teknik modelling simbolis

$\mathrm{O}=$ Post test

\section{HASIL PENELITIAN}

Pemberian posttest untuk kelas eksperimen dilaksanakan di SMK Negeri 3 Pamekasan pada tanggal 9 Juni 2016 dan posttest untuk kelas kontrol dilaksanakan di SMK Negeri I Pamekasan pada tanggal 10 Juni 2016. Posttest yang dilancarkan berupa skala harga diri, tujuannya untuk membandingkan dan mengukur harga diri remaja keluarga broken home antar kelas kontrol (tanpa treatment) dan kelas eksperimen setelah diberikan treatment berupa teknik modeling simbolis.

Data penelitian pada kelas eksperimen menunjukkan responden yang memiliki kategori harga diri sangat tinggi sebesar $5(18,5 \%)$, responden yang memiliki kategori harga diri tinggi sebesar $16 \quad(59,3 \%)$, responden yang memiliki kategori harga diri cukup 
sebesar 5 (18,5\%), responden yang memiliki kategori harga diri rendah sebesar 1 (3,7\%), dan responden yang memiliki kategori harga diri sangat rendah tidak ada $(0 \%)$.

Selanjutnya pada kelas kontrol menunjukkan responden yang memiliki kategori harga diri sangat tinggi sebesar 3 (11,1\%), responden yang memiliki kategori harga diri tinggi sebesar 11 (40,7\%), responden yang memiliki kategori harga diri cukup sebesar 11 $(40,7 \%)$, responden yang memiliki kategori harga diri rendah sebesar 2 $(7,4 \%)$, dan responden yang memiliki kategori harga diri sangat rendah tidak ada $(0 \%)$.

Tabel 1. Hasil Uji Independent Sampel ttest Harga Diri Kelompok Kontrol dan Kelompok Eksperimen

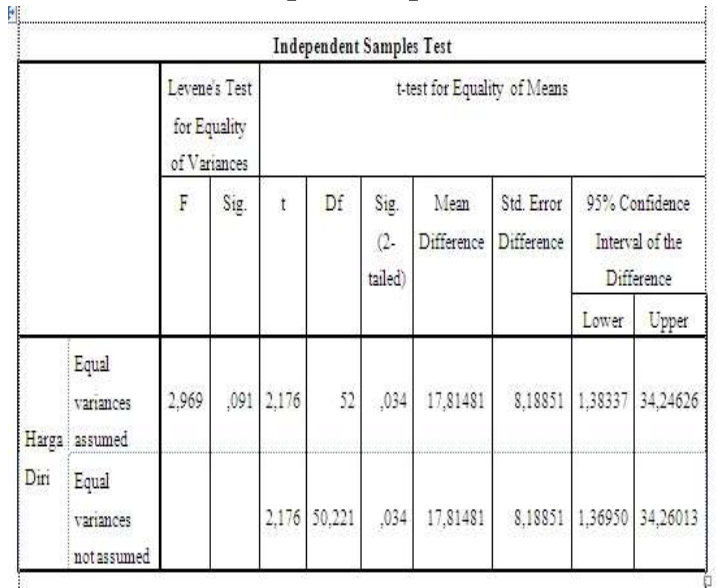

Diketahui nilai $\mathrm{F}$ hitung pada tabel harga diri kelompok kontrol dan kelompok eksperimen adalah 2,969 dengan probabilitas (Sig.) 0,091. Karena probabilitas (Sig.) 0,091 > 0,05 maka dapat disimpulkan bahwa variansi harga diri kelompok kontrol dan kelompok eksperimen tidak berbeda secara signifikan. Dengan demikian maka untuk pengujian rata-rata (t-test) mengacu pada nilai-nilai yang ada pada kolom baris asumsi varians sama.

Diketahui nilai t-hitung rata-rata skor harga diri kelompok kontrol dan kelompok eksperimen adalah $\mathrm{t}=2,176$ dengan probabilitas (Sig.) 0,034. Karena probabilitas (Sig.) 0,034<0,05 sehingga dapat disimpulkan bahwa ada perbedaan yang signifikan nilai ratarata skor harga diri kelompok kontrol dan kelompok eksperimen.

Dilihat dari nilai rata-rata dapat diketahui bahwa skor harga diri kelompok eksperimen (Mean $=165,70$ ) lebih tinggi daripada kelompok kontrol (Mean $=147,89)$ Ada perbedaan nilai rata-rata skor harga diri kelompok eksperimen dan kelompok kontrol, skor harga diri kelompok eksperimen lebih. tinggi daripada kelompok kontrol yang artinya bahwa teknik modeling simbolis efektif dalam meningkatkan harga diri remaja keluarga broken home.

\section{PEMBAHASAN}

Hasil pengujian statistik yang telah dilakukan dengan uji $t$ atau uji independent sampel t-test dapat disimpulkan bahwa ada perbedaan yang signifikan nilai rata-rata skor harga diri kelompok kontrol dan kelompok eksperimen. Jika dilihat dari rata-rata dapat diketahui bahwa skor harga diri kelompok eksperimen lebih tinggi daripada kelompok kontrol dan dari hasil tersebut dapat disimpulkan bahwa teknik modeling simbolis efektif dalam meningkatkan harga diri remaja keluarga broken home.

Murk (2006) mengatakan bahwa modelling digunakan sebagai teknik dalam meningkatkan harga diri karena dapat meningkatkan kompetensi dan merefleksikan sumber harga diri. Modeling berakar dari teori Albert Bandura dengan teori belajar sosial. Bandura (Corey, 2005) mengatakan bahwa modelling adalah suatu strategi dalam konseling yang menggunakan proses belajar melalui pengamatan terhadap model dan perubahan perilaku yang terjadi karena peniruan.

Modeling simbolis diasumsikan dapat memunculkan perilaku yang baru sesuai dengan yang ditunjukkan oleh model, 
salah satu perilaku tersebut adalah harga diri. Asumsi ini didasari dari fakta lapangan yang menunjukkan bahwa masyarakat khususnya remaja mudah terpengaruh oleh tayangan-tayangan dari televisi, dan media-media elektronik lainnya. Remaja lebih peka terhadap reaksi-reaksi lingkungan yang ada disekitarnya daripada sebelumnya, baik itu dari media massa, televisi, film atau orang-orang disekitarnya. Seperti yang diungkapkan oleh Alwisol (2009) bahwa akhir-akhir ini sebagaian besar modeling tingkah laku berbentuk simbolis, yaitu misalnya sajian dari televisi, video, film, atau media elektronik lainnya yang menyajikan perilaku yang dapat mempengaruhi pengamatnya dan sajiansajian dari media tersebut berpotensi sebagai sumber model tingkah laku, yang disebut dengan modeling simbolis.

Keefektifan teknik modeling simbolis terhadap peningkatan harga diri remaja keluarga broken home juga tidak lepas dari keefektifan media khusunya media audio visual yaitu dalam hal ini media film atau video. Penelitian sebelumnya mengenai kemampuan media, salah satunya seperti yang diungkapkan oleh Cothran (Syam dan Sugiana, 2004) diketahui bahwa media visual meningkatkan pemahaman sampai 200\% dalam pengajaran, meningkatkan daya ingat sekitar 14-38\%, dan efisiensi waktu yang diperlukan sampai $40 \%$ untuk menjelaskan konsep tunggal.

Modeling simbolis yang digunakan dalam penelitian ini adalah film yang berjudul the blind side, rumah tanpa jendela, the way home, the pursuit of happyness, 3600 detik, hearty is yoo seung ho, remember me, meet the robinsons, thank you cinta dan life as we know it. Persentasi yang disajikan berupa slide kisah orang-orang sukses dari keluarga broken home serta buku cerita/novel yang berjudul broken home $\neq$ broken dreams, ayah, peyempuan 2 dan broken home is a gift.

Berikut ini ungkapan beberapa subjek selama mengikuti proses treatment ini. Salah satu subjek yang berinisial NM dalam mengikuti treatment yaitu mengungkapkan sebagai berikut : "Setelah saya menonton film The Blind Slide, saya merasa bahwa di titik serendah apapun kita, masih ada orang di sekitar yang peduli, seperti apapun keadaan yang kita miliki tidak akan mempengaruhi impian kita".

"Setelah menonton film rumah tanpa jendela, saya dapat mengambil pelajaran bahwa disaat kita hidup dalam keluarga yang kurang memberikan perhatian, kita harus tetap kuat. Karena suatu saat mereka juga akan rindu dan ingin memberikan kasih sayangnya pada kita. Di sisi lain, jika kita hidup dalam keluarga yang kurang mampu, kita harus tetap belajar dan menjadi orang sukses agar dapat merubah nasib keluarga kita”.

"Setelah menonton film the way home, saya merasa bahwa dengan siapapun kita tinggal harus kuat dan menerimanya. Karena suatu saat kita akan menemukan kebahagiaan atau titik dimana kita inginkan. Saya bertekad harus bisa meraih apa yang saya inginkan, karena saya yakin akan ada hidup yang lebih baik yang membuat saya merasa lebih kuat. Hadapi semua kehidupan dengan tidak menyerah dan putus asa”.

Subjek yang berinisial SYN mengungkapkan sebagai berikut: "Dari semua film yang saya tonton, saya dapat mengambil pelajaran agar lebih bersabar dengan perlakuan orang tua yang selalu sibuk sendiri dan tidak memikirkan anaknya dan meskipun saya hidup dengan orang tua yang tidak lengkap, saya harus tetap memikirkan masa depan dan meraih apa yang dicitacitakan”.

Subjek yang berinisial RI mengungkapkan sebagai berikut: "Pada saat saya menonton film yang ditampilkan, seakan-akan saya menjadi tokoh yang ada di film. Saya merasakan betapa senangnya memiliki orang tua yang lengkap (ayah dan ibu). Tetapi saya 
sadar bahwa saya cuma punya ibu yang selalu bekerja demi kebutuhan sekolahku dan keluarga, sedangkan ayah saya meninggalkan saya sejak umur 2 tahun. Oleh karena itu apapun caranya saya akan berusaha untuk bisa sukses demi ibu saya dan akan membahagiakan ibu saya serta membuktikan kepada ayah saya serta orang-orang ang meremehkan saya bahwa saya bisa sukses".

Subjek yang berinisial KG mengungkapkan sebagai berikut : "Selama menghayati film yang ditampilkan, saya teringat dengan kenangan sewaktu orang tua saya masih utuh bersatu. Saya merasa agak sedih dengan keadaan yang ada sekarang, tetapi sewaktu film berada pada happy scene saya kembali merasa termotivasi dan memiliki alasan untuk sukses. Pada akhir film atau di ending, saya merasa bisa lebih menghargai hidup dan bersyukur atas semua yang di dapat dan yang saya punya hari ini. Success is for everyone because there's no key of success, you can open the door for successment".

Subjek yang berinisial LS mengungkapkan sebagai berikut : "Film Remember Me yang saya tonton ini benar-benar menyedihkan dan akhirnya membuat saya menangis dan menyentuh hati saya. Film ini juga merupakan salah satu yang terbaik karena memiliki segalanya drama, comedy dan romance. Meskipun seorang tokoh yang bernama Tyler adalah seorang yang pemberontak tetapi dia adalah lelaki yang bijaksana. Saya kagum terhadap Tyler yang ingin membahagiakan adiknya meskipun hidup keluarganya yang sangat berantakan. Hikmah yang bisa saya ambil adalah kita tidak boleh berprasangka buruk terhadap orang tua kita karena belum tentu apa yang kita fikirkan itu benar. Bukan karena orang tua kita tidak sayang, tapi karena takdir yang sudah memisahkan dan kita juga tidak boleh putus asa, karena jalan hidup ini masih panjang. Pasti akan ada kebahagiaan di balik kesedihan ini. Bagaimanapun hidup ini, kita harus tetap bisa mensyukurinya dan bagaimanapun serta sesibuk apapun orang tua kita itu hanya demi kebahagiaan kita serta memikirkan nasib kita. Tidak ada orang tua yang tidak sayang pada anak-anaknya, semua orang tua pasti menyayangi anaknya, namun dengan cara yang berbeda”.

Subjek yang berinisal HR mengungkapkan sebagi berikut : "Orang tua saya bercerai dari kecil sebelum saya lahir, jadi saya belum tahu orang tua (bapak) saya. Saya tinggal bersama ibu. Saya masih merasa beruntung mempunyai orang tau walaupun tanpa sosok seorang bapak. Saya sering sedih karena banyak orang yang bilang bahwa saya tidak punya bapak. Saya pernah menanyakan kepada ibu saya "kemana bapak?". Ibu saya bilang "bapak kamu ada, tapi tidak tahu dimana”. Hingga akhirnya saya bertekad bahwa saya akan mencari bapak. Walaupun saya sering iri melihat keluarga yang lengkap, saya selalu berdoa semoga bapak saya sehat dan suatu saat saya bisa bertemu lagi. Materi yang diberikan selama treatment ini mengingatkan saya terhadap keluarga saya. Salah satunya ketika ditayangkan film yang berjudul The Way Home, saya merasa sangat senang karena dapat mengambil hikmah dari menonton serial drama korea ini. dimana film ini hampir mirip dengan kehidupan saya. Tapi bedanya saya hidup dengan ibu saya. Ibu tidak mengeluh dengan apa yang saya minta. Walaupun tidak bisa hidup bersama kedua orang tuanya, saya melihat kakak beradik di film ini selalu tetap tegar dalam menghadapi semua masalah dengan penuh rasa saling menyayangi dan saling berbagi masalah agar tetap terselesaikan. Saya berharap dengan menonton film ini, saya bisa belajar mandiri, tidak berkecil hati dan selalu bersemangat untuk menggapai cita-cita agar kita bisa membuat orang tua senang dan bangga terhadap diri kita. 
Menurut saya terpuruk dalam kesedihan ujungnya tidak menuai kesenangan. Pada awalnya saya tidak percaya dengan diri saya. Tapi akhirnya saya yakin saya bisa melewati masalah ini dengan semangat".

Hasil observasi yang dilaksanakan saat pelaksanaan teknik modeling simbolis diketahui ada tiga orang remaja yang terharu dan menangis saat menonton film yang ditayangkan. Remaja yang lain terlihat fokus memperhatikan film dan ada yang terlihat mengobrol dengan temannya. Terlihat remaja dengan inisial WJ ini terlihat antusias dan menangis hampir di setiap treatment berupa film yang ditayangkan. Begitu juga pada sesi-sesi berikutnya dari observasi yang dilakukan terlihat ada remaja yang terharu dan menagis saat menonton film yang ditayangkan namun ada juga remaja yang sesekali berbicara dengan teman di sampingnya atau histeris ketika melihat film yang ditayangkan, jika melihat adegan-adegan yang lucu, mereka sesekali tertawa atau tersenyum.

Subjek diajak untuk fokus menonton setiap materi atau tayangan yang ditampilkan pada saat pelaksanaan eksperimen dan diminta untuk mengungkapkan secara verbal apa yang diperoleh serta diberikan kesempatan untuk memberikan umpan balik. Diskusi dan umpan balik yang diberikan diharapkan dapat memunculkan niat dalam diri untuk hidup lebih baik dan teratur serta lebih bisa menghargai diri sendiri meskipun dengan keadaan yang berbeda, karena jika kita mempunyai keyakinan dan tidak berputus asa, kita bisa lebih percaya diri, yakin akan masa depan serta menjalani hidup ini dengan lebih baik meskipun kita dari keluarga broken home. Hal ini sangat berguna dalam membangun diri dan meningkatkan harga diri subjek. Berdasarkan perhitungan statistik, wawancara, observasi dan didukung oleh beberapa teori dari beberapa ahli dapat disimpulkan bahwa teknik modeling simbolis efektif dalam meningkatkan harga diri remaja keluarga broken home.

\section{SIMPULAN}

Hasil penelitian menunjukkan bahwa ada perbedaan yang signifikan nilai rata-rata skor harga diri kelompok kontrol dan kelompok eksperimen. Skor harga diri kelompok eksperimen lebih tinggi daripada kelompok kontrol yang artinya bahwa teknik modeling simbolis efektif dalam meningkatkan harga diri remaja keluarga broken home. Hasil tersebut juga didukung oleh hasil interview atau wawancara dan observasi yang menyatakan bahwa harga diri remaja keluarga broken home yang menjadi subjek penelitian mengalami peningkatan.

Peningkatan harga diri remaja keluarga broken home tersebut terjadi karena modeling simbolis yang ditampilkan atau disajikan melalui film, video, slide, buku cerita/novel atau alat perekam lainnya dapat membantu remaja keluarga broken home dalam meningkatkan harga dirinya.

\section{DAFTAR PUSTAKA}

Abimanyu, S dan Manrihu, M. T. 1996. Teknik dan Laboratorium Konseling. Departemen Pendidikan dan Kebudayaan Direktorat Jenderal Pendidikan Tinggi. Jakarta.

Alwisol. 2009. Psikologi Kepribadian. Universitas Muhammadiyah Malang (UMM) press. Malang.

Atkinson, Rita. L, dkk. 1996. Pengantar Psikologi Jilid 1. Interaksara. Jakarta.

Baron, R.A. dan Byrne, D. 2004. Psikologi Sosial. Erlangga. Jakarta.

Chaplin, J.P. 2005. Kamus lengkap psikologi. PT Raja Grafindo Persada. Jakarta

Corey, G. 2005. Teori dan Praktek Konseling dan Psikoterapi. 
Terjemahan oleh E. Koeswara. Rafika Aditama. Bandung.

Guindon, M.H. 2010. Self Esteem Across The Life Span. Routledge. New York.

Handayani, Muryantinah Mulyo, dkk. 1998. Efektivitas Pelatihan Pengenalan Diri Terhadap Peningkatan Penerimaan Diri dan Harga Diri. Jurnal Psikologi. Universitas Gadjah Mada. No.2, 4755.

Harre, Rom dan Lamb, Roger. 1996. Ensiklopedi Psikologi Pembahasan dan Evaluasi Lengkap Berbagai Topik, Teori, Riset, dan Penemuan Baru dalam Ilmu Psikologi. Editor Edisi Indonesia : Danuyasa Asihwardji. Arcan. Jakarta.

Hidayati, N. I. L. 1995. Pengaruh Pelatihan Asertivitas terhadap Peningkatan Harga Diri. Tesis. (Tidak diterbitkan). Yogyakarta : Program Pascasarjana Universitas Gadjah Mada.

Hurlock, E. B. 1990. Psikologi Perkembangan : Suatu Pendekatan Sepanjang Rentang Kehidupan. Erlangga. Jakarta. 